\title{
Studies on Dynamic Character of Saturated Soft Clays through Cyclic Torsion Shear Tests
}

\author{
Chi $\mathrm{Li}^{1,2^{*}}$, Jianhua Wang ${ }^{1}$ and Zhenwen Liu ${ }^{1}$ \\ ${ }^{1}$ Geotechnique Engineering Institute of Tianjin University, Tianjin, 300072, China \\ ${ }^{2}$ Inner Mongolia University of Technology, Huhhot, 010051, China
}

\begin{abstract}
A large number of cyclic torsional shear tests on saturated soft clay under unconsolidated undrained condition have been carried out. The changing law between accumulative generalized shear strains vs. failure numbers has been analyzed and a cyclic shear strength curve has been received based on cyclic torsional shear tests. According to the test results, the criterion of saturated soft clay is approved on $\pi$ plane. Further, the test results are in good accord with the pseudo-static elasto-plastic creep model, which based on the cyclic triaxial tests according to the theory of pseudo-static creep. Then, dynamic character of saturated soft clay is verified from test results. The reliable proof has been provided for understanding and using dynamic character of saturated soft clay with cyclic loads, at the same time the ground has been provided for using and popularizing pseudo-static elasto-plastic cyclic strength model and pseudo-static elasto-plastic cyclic creep model.
\end{abstract}

Keywords: Ocean soils dynamics, cyclic torsional shear test, saturated soft clay, failure criterion, pseudo-static elasto-plastic cyclic creep model.

\section{INTRODUCTION}

It is a crucial project in soil dynamic field for studying the stabilization of foundation and evaluating cyclic bearing capacity of its subgrade for some large building such as offshore piping and flat roof of oil extraction with wave loads, especially for saturated soft clay strata.

Prevost [1] set up the constitutive relations of clays with cyclic loading studying the dynamic character by elastoplastic numerical method. But there are many difficulties to set up a cyclic incremental elasto-plastic model because the computing load is very large and computational error is accumulated step by step in the incremental computational procedure [2-7]. Afterwards, Wang [8, 9] developed the pseudo-static method evaluating the cyclic bearing capacity of foundation on soft clays analyzing advanced research production by former scholar. The cyclic degradation strength was first suggested, which defined degradation strength as maximum static stress after cyclic stress and the number of cycles are determined. According to the cyclic degradation strength, the cyclic bearing capacity of foundations is determined by static finite element calculation. Generally, cyclic degradation strength can be determined by cyclic triaxial tests. Then a pseudo-static elasto-plastic cyclic creep model is built through a large number of cyclic traxial tests according to the theory of pseudo-static elasto-plastic creep. The two models have high practicability in analyzing

* Address correspondence to this author at Inner Mongolia University of Technology, Huhhot, 010051, China; Tel: 86-0471-6576543; Fax: 86-04716575700; E-mail: tjdxlch2003@126.com dynamic character of soft clay with wave loads. But the parameters in the model have been defined though cyclic triaxial tests, which have limitation not reflecting the effect of middle main stress and simulating the in-situ stress state.

In this article, the dynamic character of saturated soft clay under UU condition has been studied through large number of cyclic torsional shear tests. To analyze the test results on $\pi$ plane, Mises criterion can be used to describe the failure behavior of saturated soft clay. This conclusion is in good accord with result from cyclic triaxial tests. Further, cyclic torsional shear test results has goodness of fit to the pseudo-static elasto-plastic cyclic creep model come from cyclic triaxial test results. Because cyclic torsional test is better than cyclic triaxial test in simulating general stress state. It is the theory basis for using and popularizing pseudo-static elaseo-plastic cyclic strength model and pseudo-static elasto-plastic cyclic creep model.

\section{CYCLIC TORSIONAL SHEAR TEST}

\section{The Soil Testing and Specimen Preparation}

Saturated soft clay has been remolded with vacuum preloading. It has even water content and in well grain series. According to the liquid limit and plastic limit index, it has been named highly liquid limit clay. The basic soil properties parameters are shown in Table $\mathbf{1 .}$

\section{Testing Apparatus}

"Civil engineering static-cyclic hydraulic pressure triaxial-torsional shear multifunctional shear apparatus" shown in Fig. (1) is designed and facilitated by Dalian University of Technology under the cooperation of Seiken Inc., 
Table 1. Soil Properties Parameters

\begin{tabular}{|c|c|c|c|}
\hline $\begin{array}{c}\text { Average } \\
\text { Water } \\
\text { Content }\end{array}$ & $\begin{array}{c}\text { Average } \\
\text { Unit } \\
\text { Weight }\end{array}$ & Plastic Limit & Liquid \\
Limit & Plastic Index \\
\hline \hline $38.5 \%$ & $1.8 \mathrm{~g} / \mathrm{cm}^{3}$ & $19.8 \%$ & $40.8 \%$ \\
\hline \multirow{2}{*}{ Liquid index } & $\begin{array}{c}\text { Static UU shear } \\
\text { strength }\end{array}$ & clay grain $(<0.005)$ & Grain size analysis \\
\cline { 2 - 4 } & $12 \mathrm{kPa}$ & $34.7 \%$ & silt grain $(0.005 \sim 0.05)$ \\
\hline 0.89 & & $51.6 \%$ \\
\hline
\end{tabular}

Japan [10]. This apparatus can reproduce isotropic consolidation, anisotropic consolidation with different initial conditions, $\mathrm{K}_{0}$ consolidation. It can be used for complex stress states and stress path including static and cyclic triaxial test, static and cyclic torsional test, the continuous rotation of principal stress axes and can be used perform various soil experimental tests on sands or clays. It is fulfilled the precision requirement for small strain behavior and large strain behavior. In this test, cyclic torsional shear test under UU condition has been conducted on saturated soft clay according to two confining pressure $50 \mathrm{kPa}$ and $100 \mathrm{kPa}$. The specimens were prepared with initial dimensions as follows: inner diameter $3 \mathrm{~cm}$, external diameter $7 \mathrm{~cm}$ and height $10 \mathrm{~cm}$ in cyclic torsional shear tests. The middle main stress modulus is 0.5 , main stress deflexion angle is $45^{\circ}$ and initial deviator stress ratio is 0 .

\section{Stress State of Soil Element}

Single torsional shear test was conducted under UU with the same confining pressure in inner and outer cavity. During the test, static shear stress was loaded at beginning then cyclic shear stress was loaded considering coupling of static and cyclic stress. Ratios of static shear stress and cyclic shear stress were considered in order to reduce the effect of not uniformity and exert load according to deformation. The stress state of soil element was shown in Fig. (2).

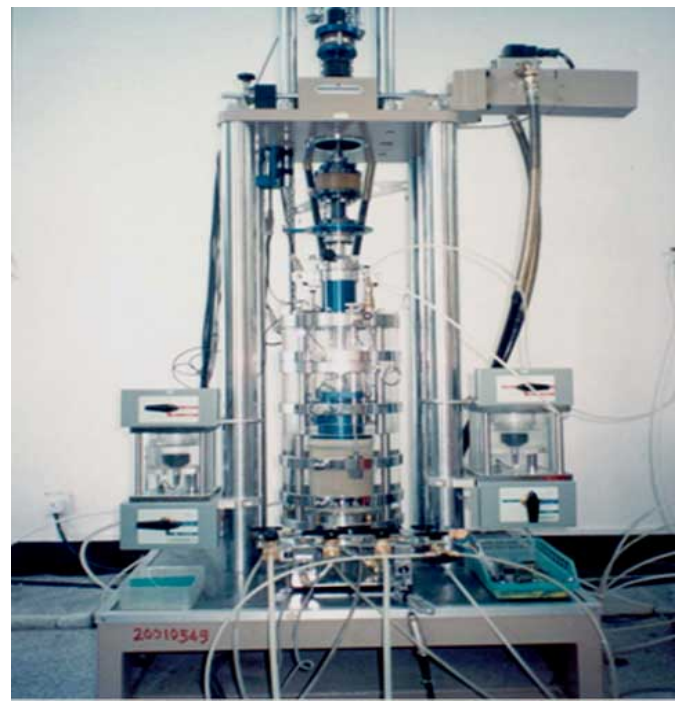

Fig. (1). Testing apparatus.
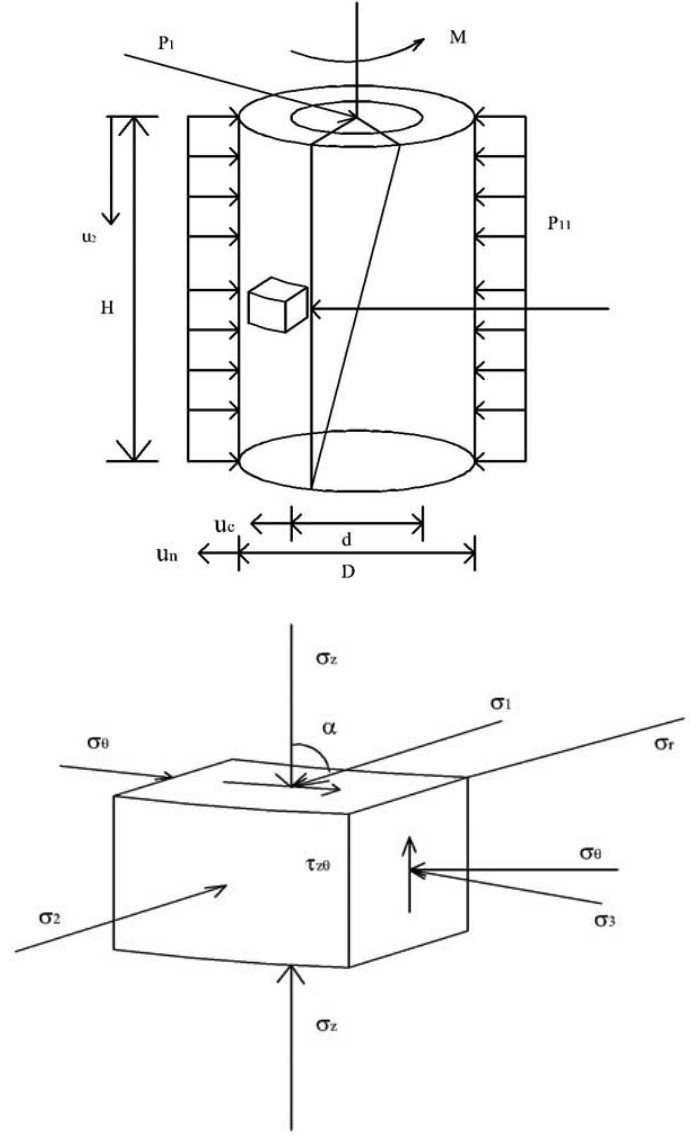

Fig. (2). Stress State of Soil Element.

\section{TEST CONTENT AND TEST RESULTS}

Static torsional shear test results show in Fig. (3) under UU conditions.

\section{Accumulative Generalized Shear Strain}

Accumulative genelarized shear strain under different static and cyclic stress combination was computed by equation (1). The strain of vertical, radial, circumferential and shear strain have been collected in CTS test. The relationship of accumulative genelarized shear strain $\gamma_{g} v s$. failure num- 


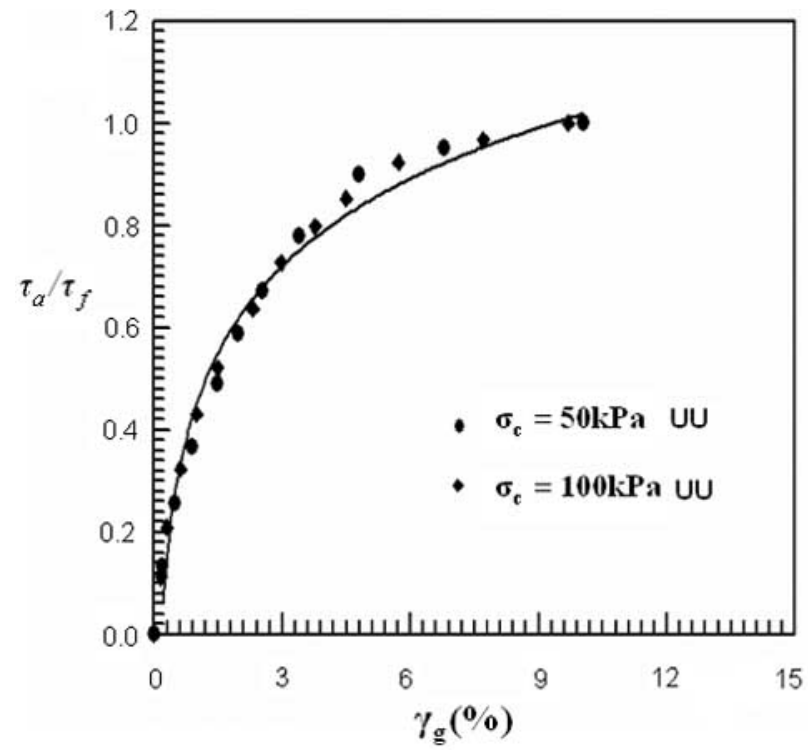

Fig. (3). static cyclic torsional shear test.

bers $N_{f}$ was analyzed, which showed in Fig. (4) and Fig. (5) according to two confining pressure.

$\gamma_{g}=\frac{\sqrt{2}}{3} \sqrt{\left(\varepsilon_{1}-\varepsilon_{2}\right)^{2}+\left(\varepsilon_{2}-\varepsilon_{3}\right)^{2}+\left(\varepsilon_{1}-\varepsilon_{3}\right)^{2}}$

In equation (1),

$$
\begin{aligned}
& \varepsilon_{1}=\frac{\varepsilon_{z}+\varepsilon_{\theta}}{2}+\frac{1}{2} \sqrt{\left(\varepsilon_{z}-\varepsilon_{\theta}\right)^{2}+\gamma_{z \theta}^{2}} \\
& \varepsilon_{2}=\varepsilon_{r} ; \\
& \varepsilon_{3}=\frac{\varepsilon_{z}+\varepsilon_{\theta}}{2}-\frac{1}{2} \sqrt{\left(\varepsilon_{z}-\varepsilon_{\theta}\right)^{2}+\gamma_{z \theta}^{2}} ; \\
& \varepsilon_{z}=\frac{u_{z}}{H_{c}} ; \\
& \varepsilon_{r}=-2 \frac{u_{0}-u_{i}}{D_{c}-d_{c}} ; \\
& \varepsilon_{\theta}=-2 \frac{u_{0}+u_{i}}{D_{c}+d_{c}} ; \\
& \gamma_{z \theta}=2 \varepsilon_{z \theta}=\frac{\theta\left(d_{t}-d_{c}\right)}{3 H_{c}\left(D_{c}^{2}-d_{c}^{2}\right)} ;
\end{aligned}
$$

Where: $\varepsilon_{1}, \varepsilon_{2}, \varepsilon_{3}$ large main stress, middle main stress, small main stress;

$$
\varepsilon_{z}, \varepsilon_{r}, \varepsilon_{\theta}, \gamma_{z \theta} \text { vertical strain, radial strain, circumfer- }
$$
ential strain, shear strain;

$$
u_{z}, u_{0}, u_{i} \text { vertical displacement, inner radial displace- }
$$

ment, outer radial displacement during shear;
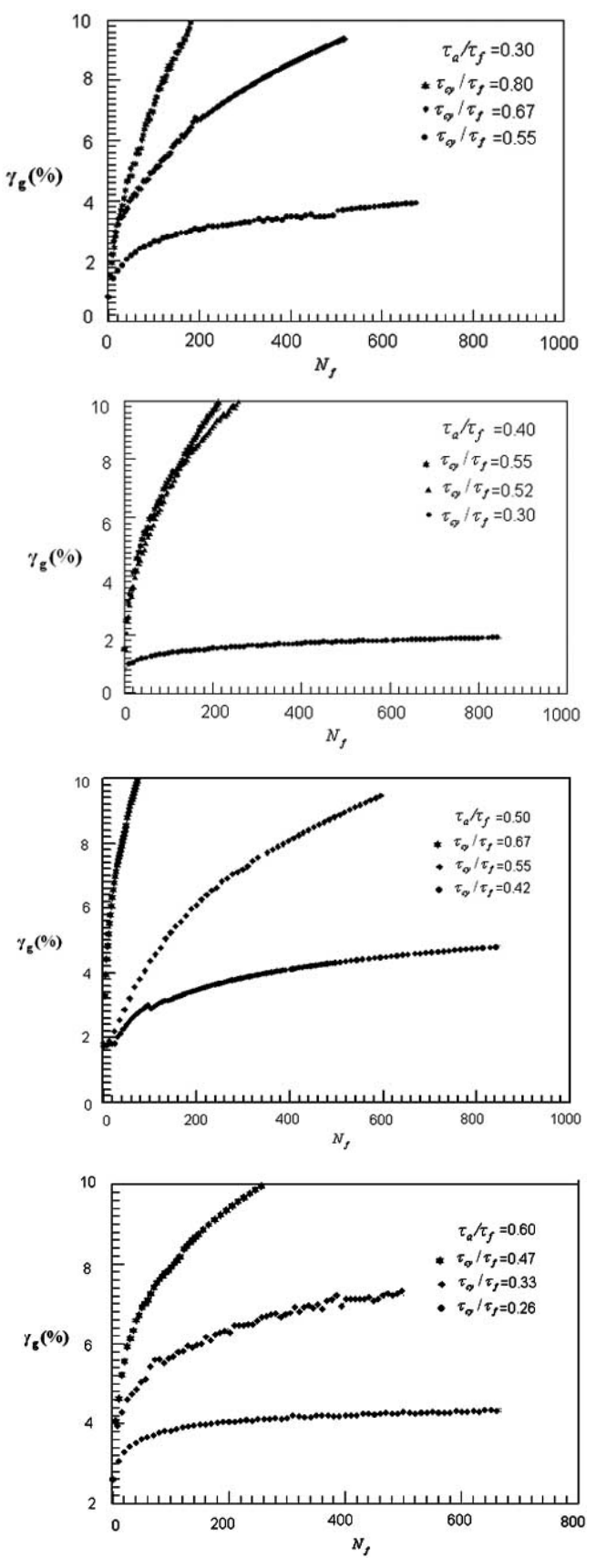

Fig. (4). $\gamma_{g} \sim N_{f}\left(\sigma_{c}=50 \mathrm{kPa}\right)$. 
$D_{c}, d_{c}, H_{c}$ initial outer diameter, inner diameter, height ;

$D_{t}, d_{t}$ outer diameter, inner diameter during shear;
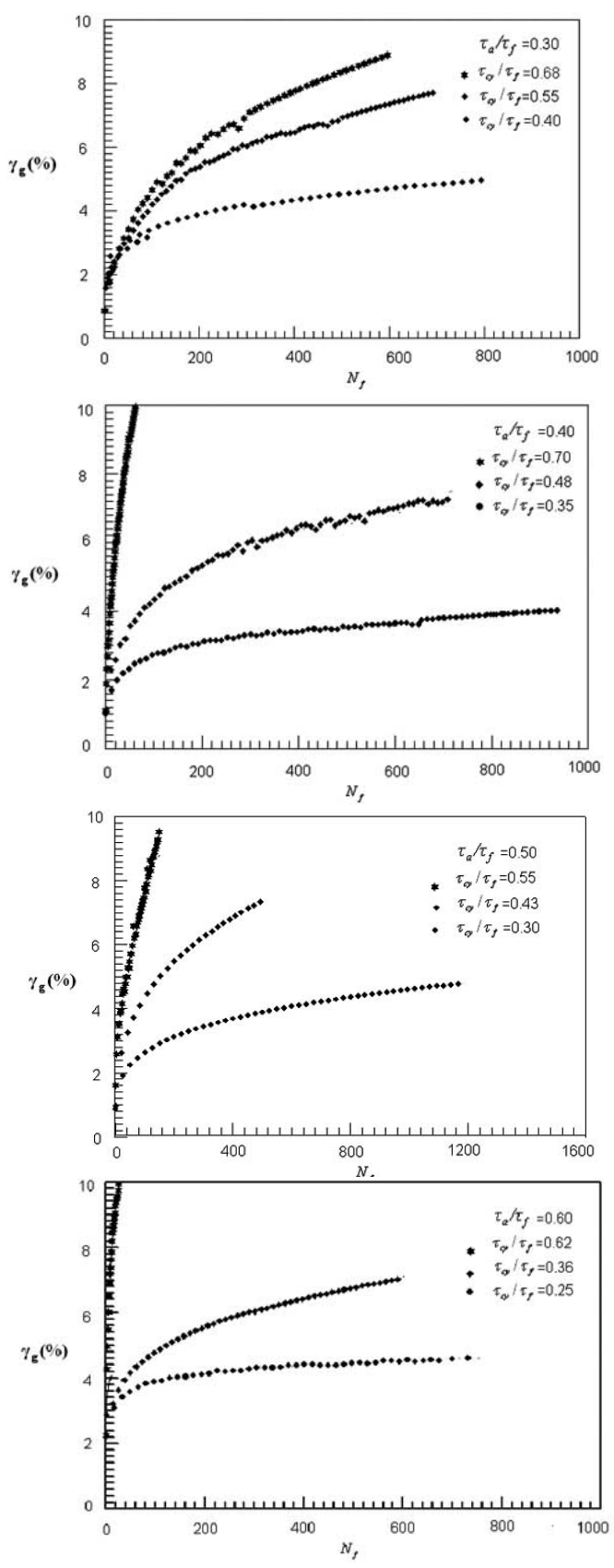

Fig. (5). $\gamma_{g} \sim N_{f}\left(\sigma_{c}=100 \mathrm{kPa}\right)$.

\section{Cyclic Shear Strength Curves} (2):

Cyclic shear strength in CTS test is defined as equation

$$
\tau_{f, c y}=\left(\tau_{a}+\tau_{c y}\right)_{f}
$$

Where ${ }^{\tau_{8}}$ octahedral shear stress; ${ }^{\tau_{8 j}}$ octahedral static shear stress; ${ }^{\tau_{f}}$ static shear strength; $\tau_{a}$ static shear stress before shearing; $\boldsymbol{\tau}_{c y}$ cyclic shear stress during shear

Based on the relationship between accumulative generalized shear strain and number of cycles, cyclic shear strength curves can be determined with different static shear stress ratios according to certain failure standard. Cyclic shear strength curves are shown in Fig. (6) according to different confining pressure.
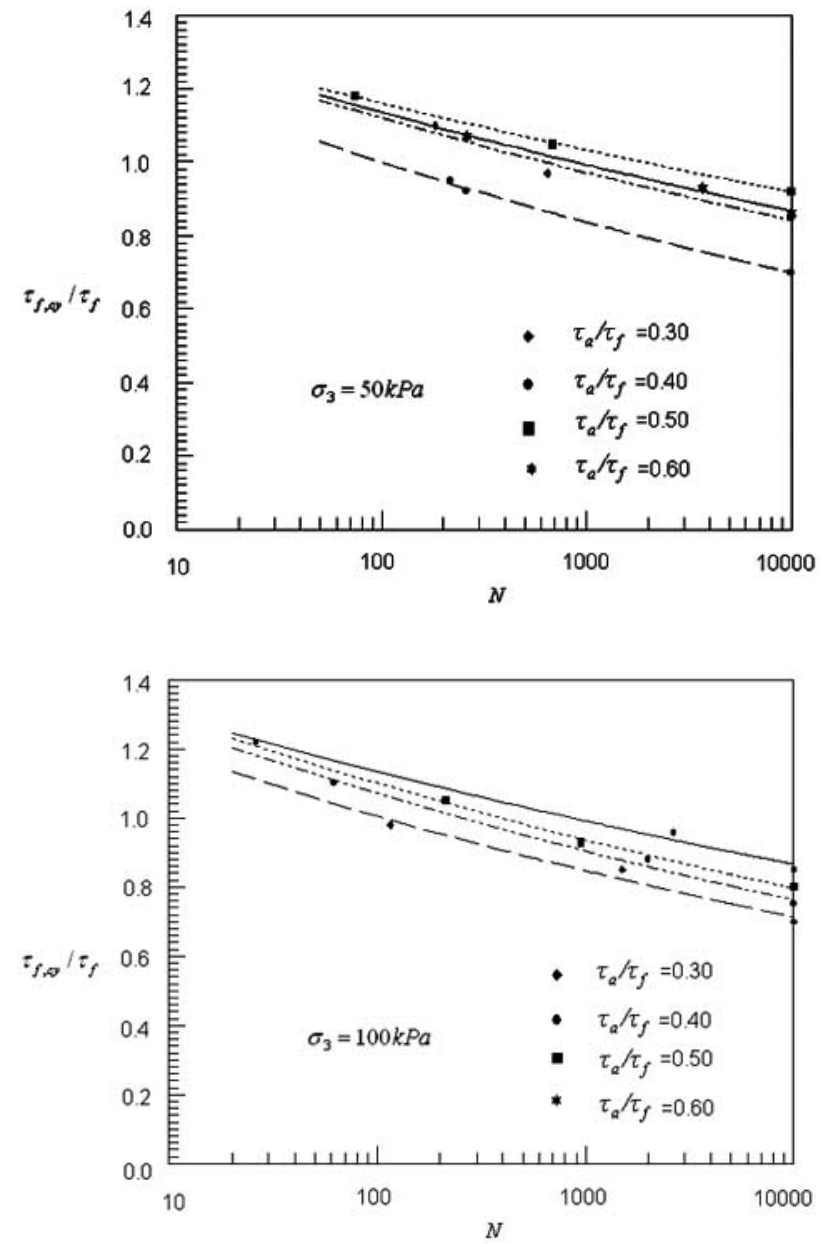

Fig. (6). Cyclic shear strength curves in CTS test.

\section{Failure Shape}

Cyclic stress has great effect on the soil at beginning in CTS test and the extend phenomena is not serious in CTS test than in CTX test. So cyclic shear strength of saturated soft clay may be more in CTS test than that's in CTX test. During cyclic torsional shearing, compression is not obviously in lengthwise direction; inverse shrinkage distortion is large in round and in radial. The volume of inner cavity has continuous shrinking. The detail of deformation is shown in Fig. (7). 


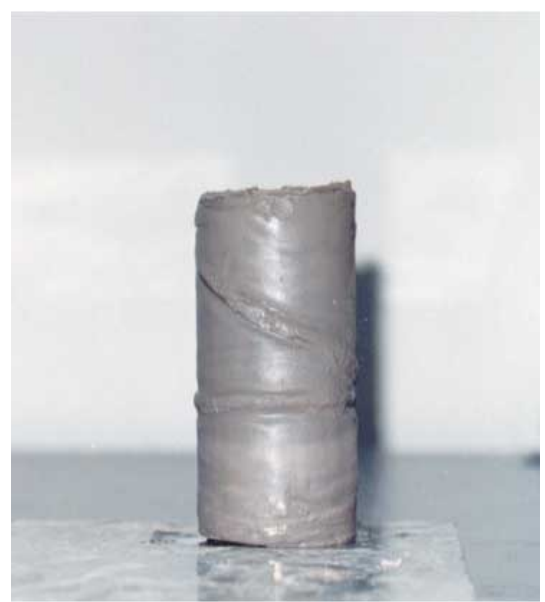

Fig. (7). Failure shape of saturated soft clay sample.

\section{VERIFICATION OF THE CRITERION}

The shape function of some criterions on $\pi$ plane can be summarized to $F=\alpha_{1} p-k+\overline{\sigma_{+}}=0$. Where, $\overline{\sigma_{+}}=\frac{\sqrt{J_{2}}}{g\left(\theta_{\sigma}\right)}$ and $g\left(\theta_{\sigma}\right)$ is the shape function. Some parameters can be showed in Table 2 with seven kinds of criterion. The three main stresses have been computed though collecting the change of inner and outer diameter as well as inner cavity volume. Results have been shown in Fig. (8) on $\pi$ plane according to the even shear stress and generalized shear stress. It is clear that cyclic failure of saturated soft clays followed Mises criterion under UU. So, pseudo-static elasto-
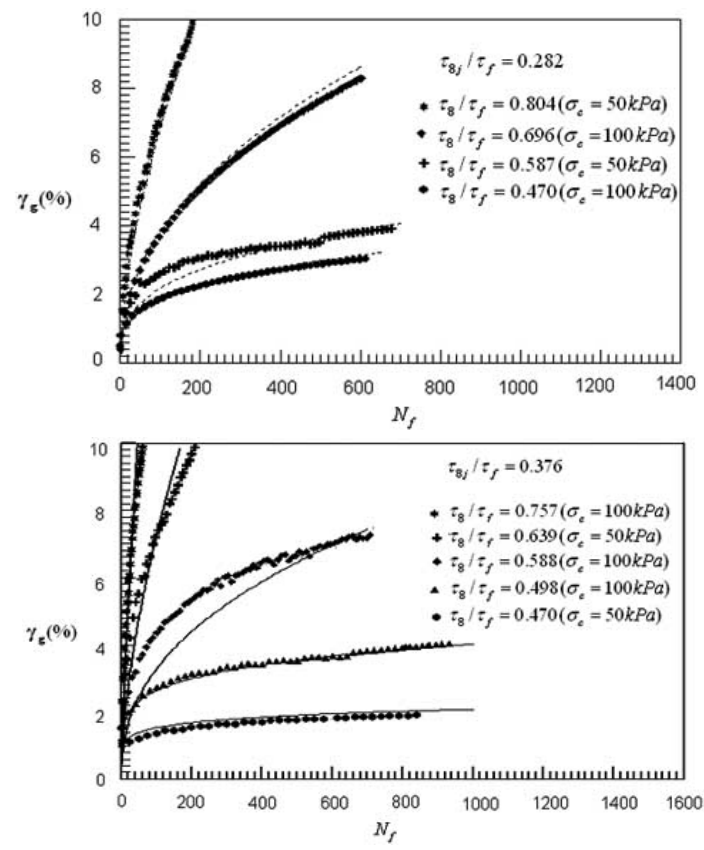

plastic cyclic strength model can be popularized to general stress state based on the Mises criterion.

Where:

$$
\begin{gathered}
\sigma_{1}=\sigma_{c}+\sqrt{\tau_{a}{ }^{2}+\tau_{c y}{ }^{2}} \\
\sigma_{2}=\sigma_{c} \\
\sigma_{3}=\sigma_{c}-\sqrt{\tau_{a}{ }^{2}+\tau_{c y}{ }^{2}} \\
p=\frac{\sigma_{1}+\sigma_{2}+\sigma_{3}}{3} \\
q=\frac{1}{\sqrt{2}} \sqrt{\left(\sigma_{1}-\sigma_{2}\right)^{2}+\left(\sigma_{1}-\sigma_{3}\right)^{2}+\left(\sigma_{2}-\sigma_{3}\right)^{2}}
\end{gathered}
$$

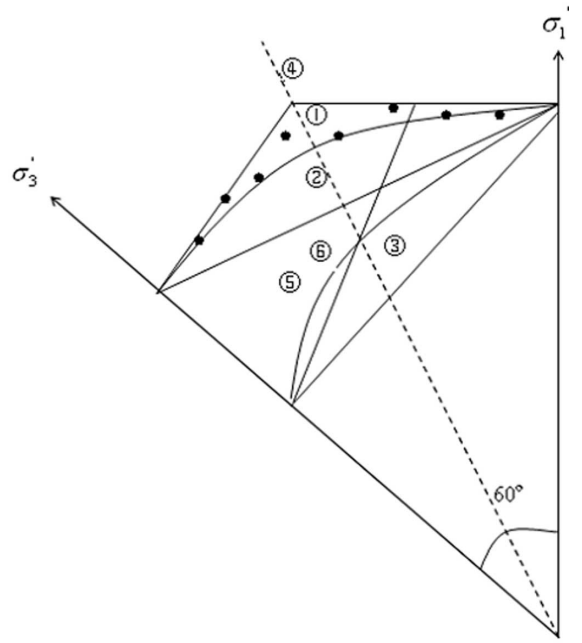

Fig. (8). $\pi$ plane sketch.
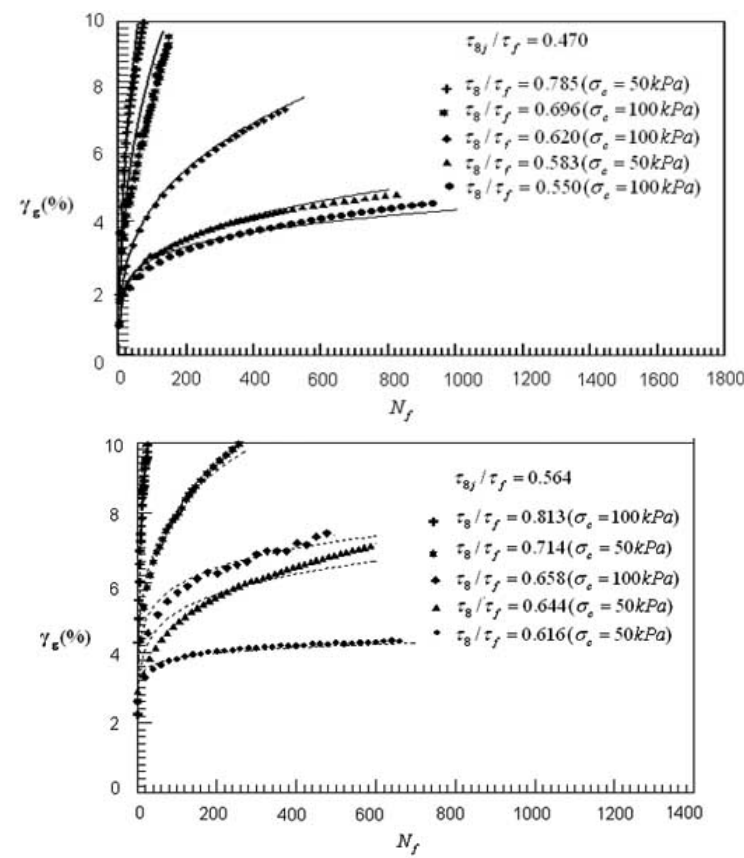

Fig. (9). Fitting results between creep model and cyclic torsional shear test. 
Table 2. Computing Parameters of Different Criterion

\begin{tabular}{|c|c|c|c|}
\hline Criterion & $\alpha_{1}$ & $k$ & $g\left(\theta_{\sigma}\right)$ \\
\hline Mises & 0 & $\sqrt{J_{2}}$ & 1 \\
\hline Drucker-Prager & $\frac{3 \sin \varphi}{\sqrt{3} \sqrt{3+\sin ^{2} \varphi}}$ & $\frac{3 c \cos \varphi}{\sqrt{3} \sqrt{3+\sin ^{2} \varphi}}$ & 1 \\
\hline Tresca & 0 & $\frac{2 \sqrt{J_{2}}}{\sqrt{3}}$ & $\frac{\sqrt{3}}{2 \cos \varphi_{\sigma}}$ \\
\hline Mohr-Coulomb & $\frac{6 \sin \varphi}{\sqrt{3}(3-\sin \varphi)}$ & $\frac{6 c \cos \varphi}{\sqrt{3}(3-\sin \varphi)}$ & $\frac{3-\sin \varphi}{2\left(\sqrt{3} \cos \theta_{\sigma}-\sin \theta_{\sigma} \sin \varphi\right)}$ \\
\hline Double-shear & 0 & $\frac{2 \sqrt{J_{2}}}{\sqrt{3}}$ & $\begin{array}{l}\frac{1}{\frac{\sqrt{3}}{2} \cos \theta_{\sigma}-\frac{1}{2} \sin \theta_{\sigma}}, \theta_{\sigma} \leq 0^{\circ} \\
\frac{1}{\frac{\sqrt{3}}{2} \cos \theta_{\sigma}+\frac{1}{2} \sin \theta_{\sigma}}, \theta_{\sigma} \geq 0^{\circ}\end{array}$ \\
\hline Generalized double shear & $\frac{6 \sin \varphi}{\sqrt{3}(3-\sin \varphi)}$ & $\frac{6 c \cos \varphi}{\sqrt{3}(3-\sin \varphi)}$ & $\begin{array}{l}\frac{K}{\frac{\sqrt{3}}{2} \cos \theta_{\sigma}-\frac{1}{2} \sin \theta_{\sigma}}, \theta_{\sigma} \leq \operatorname{tg}^{-1}\left(\frac{1}{\sqrt{3}} \sin \varphi\right) \\
\frac{K}{\frac{\sqrt{3}}{2} \cos \theta_{\sigma}+\frac{1}{2} \sin \theta_{\sigma}}, \theta_{\sigma} \geq \operatorname{tg}^{-1}\left(\frac{1}{\sqrt{3}} \sin \varphi\right)\end{array}$ \\
\hline Matsuoka-Nakai & $\frac{6 \sin \varphi}{\sqrt{3}(3-\sin \varphi)}$ & $\frac{6 c \cos \varphi}{\sqrt{3}(3-\sin \varphi)}$ & $\begin{array}{l}2 \alpha_{1}^{3}\left(\alpha_{1}^{2}-9\right) \sin \theta_{\sigma} g^{3}\left(\theta_{\sigma}\right)+\left(2 \alpha_{1}^{5}-54 \alpha_{1}^{2}\right) g^{2}\left(\theta_{\sigma}\right) \\
-18 \alpha_{1}^{3}+54 \alpha_{1}^{2}=0\end{array}$ \\
\hline
\end{tabular}

Where : $c, \varphi$ cohesive strength, inner friction angle; $\theta_{\sigma}$ Lode angle; $J_{2}$ the second invariant of $\operatorname{stress}$ tensor; $K=\frac{3+\sin \varphi}{3-\sin \varphi}$;

\section{Pseudo-Static Elasto-Plastic Cyclic Creep Model}

If the number of cycles is considered as the time during static creep and the accumulative strain at the end of one cycle is considered as pseudo-static creep [11], then pseudostatic elasto-plastic cyclic creep model can be built by the elasto-plastic theory $[9,12]$. Cyclic torsional shear test results have been fitted with the pseudo-static elasto-plastic creep model, which built according to the theory of pseudostatic elasto-plastic creep through a lot of cyclic triaxial tests. There is a surprising finding that the deformation of soft clay has a goodness of fit in two different tests. Imaginal line is the computing results from creep model and different dots represent the test results with different static and cyclic stress combination, showed in Fig. (9).

\section{CONCLUSIONS}

A changing law of accumulative generalized shear strain vs. failure numbers has been analyzed though a large number of cyclic torsional shear tests and cyclic shear strength curves have been gained according to certain failure criterion. The saturated soft clays have been verified to following Mises criterion under cyclic loads on $\pi$ plane. Based on the theory of pseudo-static creep and yield criterion, cyclic torsional shear test results are in good accord with pseudo-static 
elasto-plastic cyclic creep model, which result from cyclic triaxial test results using octahedral shear stress and octahedral static shear stress in the model.

There are two different testing stress states between cyclic triaxial test (CTX) and cyclic torsional shear test (CTS). But CTS more approach to general stress state than CTX. It is reliable that CTS results have been used to verify saturated soft clays dynamic character based on CTX results. But also it is a new break through in soil dynamic field. Even else, theory basis have been provided for using and popularizing pseudo-static elasto-plastic cyclic strength model and pseudo-static elasto-plastic cyclic creep model.

\section{ACKNOWLEDGEMENT}

This project was financially by the NSFC (Grant No. 50379035).

\section{REFERENCES}

[1] J. H. Prevest, "Mathematical modelliing of monotonic and cyclic undrained clay behavior," International Journal for Numerical and Analytical Methods in Gemechanics, vol. 1, no. 1, pp. 195-216, April 1981.

[2] W.A. Marr, and J. T. Christian, "Permanent displacements due to cyclic wave loading," Journal of Geotechnical Engineering, ASCE, vol. 107, no. GT8, pp. 1129-1149, August 1981.

[3] G. Bouckovalas, W.A. Marr, and J.T. Christian, "Analyzing permanent drift due to cyclic load," Journal of Geotechnical Engineering, ASCE, vol. 12, no. GT6, pp. 579-593, May 1986.
[4] K. H. Andersen, and R. Lauritzsen, "Bearing capacity for foundations with cyclic loads," Journal of Geotechnical Engineering, vol. 114, No. 5, pp. 540-555, May 1988.

[5] Cathie, D.N. "A soil model for the evaluation of displacement and pore pressures in foundation of offshore gravity structures subjected to cyclic loading," In: International Symposium on Numerical Models in Geomechanics, 1982, pp. 368-376.

[6] I. Foss, R. Dahlberg, and T. Kvalstad, "Foundation design for gravity structures with respect to failure in cyclic loading," In: Offshore Technology Conference, 1978, Paper. 3114.

[7] Y.R. Zheng, Z.J. Shen, and X.N. Gong, "The principles of geotechnical plastic mechanics". Beijing: China Architecture and Building Press, 2002. (in Chinese)

[8] J.H. Wang, Z.W. Liu, and Y.F. Liu, "Estimation of undrained bearing capacity for offshore soft foundation with cyclic loads,"China Ocean Engineering, vol. 12, no. 5, pp. 213-222, February 1998.

[9] J.H. Wang, Z.W. Liu, and Z. R. Qin, "Pseudo-Static elasto-plastic cyclic creep model and cyclic stability of offshore soft foundation," China Ocean Engineering, vol. 13, no. 3, pp. 247-256, March 1999.

[10] Y. Guo, "Experimental studies on undrained behavior of loose sands under complex stress conditions considering static and cyclic couping effect," A dissertation for degree of doctor of engineering, Dalian, Dalian University of Technology, 2003 (in: Chinese)

[11] A.F.L. Hyde, and S.F. Brown, "The plastic deformation of silty clay under creep and repeated loading," Geotechnique, vol. 26, no. 1, pp. 173-184, March 1976.

[12] C. Li, and J.H. Wang, "Cyclic torsional shear experimental studies on dynamics characters for saturated soft clay strata," Rock and Soil Mechanics, vol. 29, no. 2, pp. 460-464, 2008.

(C) Li et al.; Licensee Bentham Open.

This is an open access article licensed under the terms of the Creative Commons Attribution Non-Commercial License (http://creativecommons.org/licenses/by-nc/3.0/) which permits unrestricted, non-commercial use, distribution and reproduction in any medium, provided the work is properly cited. 